\title{
Dose comparison of ultrasonic transdermal insulin delivery to subcutaneous insulin injection
}

\author{
Eun-Joo Park' \\ Jeff Dodds² \\ Nadine Barrie Smith ${ }^{3}$ \\ 'Department of Bioengineering, \\ ${ }^{2}$ Animal Resource Program, \\ ${ }^{3}$ Graduate Program in Acoustics, \\ The Pennsylvania State University, \\ University Park, PA, USA
}

\begin{abstract}
Prior studies have demonstrated the effectiveness of noninvasive transdermal insulin delivery using a cymbal transducer array. In this study the physiologic response to ultrasound mediated transdermal insulin delivery is compared to that of subcutaneously administered insulin. Anesthetized rats $(350-550 \mathrm{~g})$ were divided into four groups of four animals; one group representing ultrasound mediated insulin delivery and three representing subcutaneously administered insulin $(0.15,0.20$, and $0.25 \mathrm{U} / \mathrm{kg})$. The cymbal array was operated for 60 minutes at $20 \mathrm{kHz}$ with $100 \mathrm{~mW} / \mathrm{cm}^{2}$ spatial-peak temporal-peak intensity and a $20 \%$ duty cycle. The blood glucose level was determined at the beginning of the experiment and, following insulin administration, every 15 minutes for 90 minutes for both the ultrasound and injection groups. The change in blood glucose from baseline was compared between groups. When administered by subcutaneous injection at insulin doses of 0.15 and $0.20 \mathrm{U} / \mathrm{kg}$, there was little change in the blood glucose levels over the 90 minute experiment. Following subcutaneous administration of insulin at a dose of $0.25 \mathrm{U} / \mathrm{kg}$, blood glucose decreased by $190 \pm 96 \mathrm{mg} / \mathrm{dl}$ (mean $\pm \mathrm{SD}$ ) at 90 minutes. The change in blood glucose following ultrasound mediated insulin delivery was $-262 \pm 40 \mathrm{mg} / \mathrm{dl}$ at 90 minutes. As expected, the magnitude of change in blood glucose between the three injection groups was dependant on the dose of insulin administered. The change in blood glucose in the ultrasound group was greater than that observed in the injection groups suggesting that a higher effective dose of insulin was delivered.
\end{abstract}

Keywords: ultrasound, intensity, drug delivery, insulin, injections

\section{Introduction}

Transdermal drug delivery has been studied as an alternative method for noninvasive drug administration. However, the use of this method has been limited because the superficial layer of the skin, the stratum corneum, is not sufficiently permeable to allow effective transfer of medication into the bloodstream. To enhance transportion of drugs through the skin, several approaches, including chemical enhancers (Johnson et al 1996), iontophoresis (Wang et al 2005), microneedles (Nanda et al 2006), electroporation (Prausnitz et al 1993, 2004) and ultrasound (Pitt et al 2004; Mitragotri and Kost 2004; Smith 2007) have been studied as an alternative to needles. Currently, the transdermal transport of insulin is of interest due to the current 21 million Americans who have this disease (CEDR 1999; The Whitaker Foundation 2004; Hussain et al 2007). Diabetes is one of the most costly ailments and its management often requires painful, repetitive insulin injections as often as four times each day.

Of the experiments using ultrasound, many were focused on the feasibility of the approach (Tachibana and Tachibana 1991; Boucaud et al 2002; Lee et al 2004a). Some researchers have studied the effects of frequencies and intensities on the effectiveness of ultrasonic delivery in an effort to understand the mechanisms by which ultrasound enhances transdermal delivery (Machet and Boucaud 2002; Merino et al 2003; Schlicher et al 2006). While ultrasound is effective, the relationship between the 
intensities and potential bioeffects has yet to be determined (Wu et al 1998; Doukas and Kollias 2004). Additionally there is limited understanding as how the intensities relates to the amount of insulin transported via ultrasound (Luis et al 2007) or to direct injections. To date, many ultrasound drug delivery experiments on enhanced transdermal drug delivery are performed using sonicators, ultrasonic baths, or commercially made ("off-the-shelf") transducers (Tachibana and Tachibana 1991; Santoianni et al 2004; Pitt et al 2004; Smith 2007). The large sizes of these devices and the difficulty of transporting them have been significant disadvantages associated with their practical use for noninvasive drug delivery. Commercial sonicators are large, heavy, tabletop devices specially designed for lysis of cells or catalyzing reactions. In order to become a practical portable ultrasound device, there is the need for a smaller transducer which can work in the same frequency range (Pitt et al 2004). Additionally it is important to balance ultrasound safety (dosimetry) versus efficacy since large intensities can also cause damage (Wu et al 1998; Lee et al 2005).

To meet the demand for a practical portable device, a small-sized, low-profile, and lightweight cymbal transducer has been used for the transdermal delivery of insulin. This flextensional transducer has a thickness of less than $2 \mathrm{~mm}$, weighs less than 3 grams and resonates between 1 and $100 \mathrm{kHz}$ (Newnham et al 1991; Maione et al 2002). The cymbal transducer array has previously demonstrated enhancement in transport of insulin for in vitro human skin (Smith et al 2003a), in vivo rats (Smith et al 2003b), rabbits (Lee et al 2004b; Snyder et al 2006), and large pigs (Park et al 2007). One of the many questions with this approach is the relationship between the levels of glucose decrease from ultrasound versus a direct subcutaneous injection of insulin. Therefore the purpose of this research is to examine the blood glucose response from direct injections of insulin against the ultrasound intensity from a cymbal array.

\section{Materials and methods}

\section{Ultrasound transducer array}

Details regarding the design and construction of the cymbal transducer and the multi-element array have been described elsewhere (Newnham et al 1991, 1994; Maione et al 2002). Briefly, the cymbal transducer is a novel flextensional transducer capable of producing very low frequencies (Figure 1a). A cymbal transducer has a compact, lightweight structure with an adjustable resonance frequency. In the cymbal transducer design, the caps on the lead zirconate - titanate (PZT) ceramic contained a shallow cavity beneath the inner surface.
The fundamental mode of vibration is the flexing of the end caps caused by the radial motion of the ceramic. Therefore, the overall displacement of the device is a combination of the axial motion of the disk plus the radial motion amplified by the end caps. Amplification factors can be as high as 40 times that of the ceramic by itself (Meyer et al 2001). Specifically, the piezoelectric disc was made from PZT-4 (Piezokinetics, Inc., Bellefonte, PA), had a diameter of $12.7 \mathrm{~mm}$, and was $1 \mathrm{~mm}$ thick. Caps were made of $0.25-\mathrm{mm}$ thick titanium while the thin glue layer between the caps and the ceramic disk was made of Eccobond ${ }^{\circledR}$ (Emerson and Cuming, Billerica, MA) epoxy. For the array, four transducers were connected in parallel and encased in URALITE ${ }^{\circledR}$ polymer (FH 3550, H.B. Fuller, St. Paul, MN) to produce a transducer array arrangement.

The array was driven by a radio frequency (RF) signal generated by a pulse/function generator (Model 393, Wavetek Inc., San Diego, CA) and amplified by an RF amplifier (Model 40A12, Amplifier Research, Souderton, PA). The electrical impedance of the array was matched to the output impedance of the amplifier by an external inductor-capacitor tuning network. Pulse period, duty cycle, and exposure time of the RF signal from the frequency generator was monitored using an oscilloscope (Tektronix 2213A, Beaverton, OR). For the ultrasound exposure experiments, the array was operated at $20 \mathrm{kHz}$ with a pulse duration of $200 \mathrm{~ms}$ and a pulse repetition period of 1 second (ie, 20\% duty cycle). Pulsed ultrasound was used to avoid damaging either the array or the animal's skin by excessive heat generation.

\section{Ultrasound exposimetry}

The intensity was determined according to exposimetry guidelines established by the American Institute of Ultrasound in Medicine (IEEE 1990; AIUM 1998). For the acoustic field at a plane $1 \mathrm{~mm}$ from the transducer face, the ultrasonic intensities from the array were measured with a calibrated miniature ( $4 \mathrm{~mm}$ diameter) omnidirectional reference hydrophone (Model TC4013, S/N: 5199093, RESON, Inc., Goleta, CA). The cymbal array was submerged in a water tank $\left(51 \times 54 \times 122 \mathrm{~cm}^{3}\right)$ which was made almost anechoic by placing $1.27 \mathrm{~cm}$ thick rubber sound absorbing material around its wall. A custom made degasser, built in-house, reduced the dissolved oxygen content of the distilled water to 1-2 ppm to reduce cavitation effects. Pulse period, duty cycle and exposure time of the signal from the frequency generator and hydrophone was acquired using an Agilent 54622A 100 MHz digitizing oscilloscope (Agilent, Palo Alto, CA). 
A

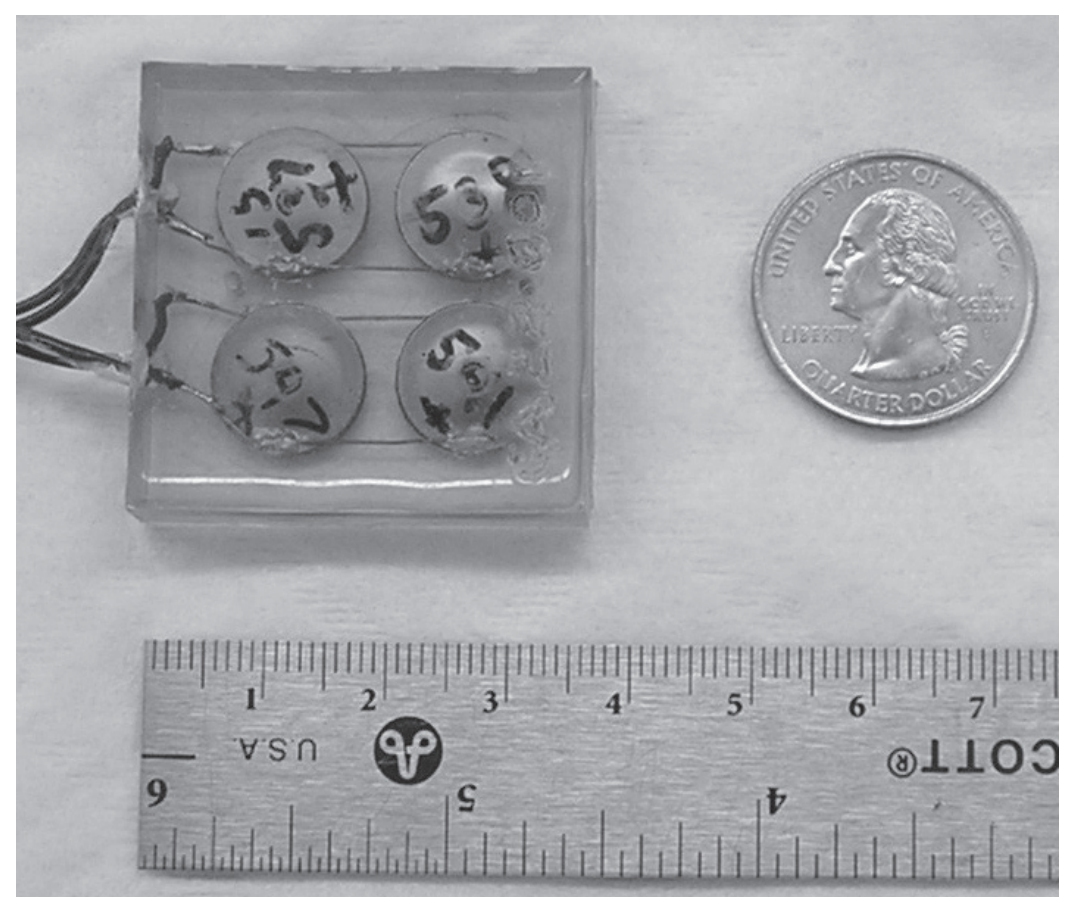

B

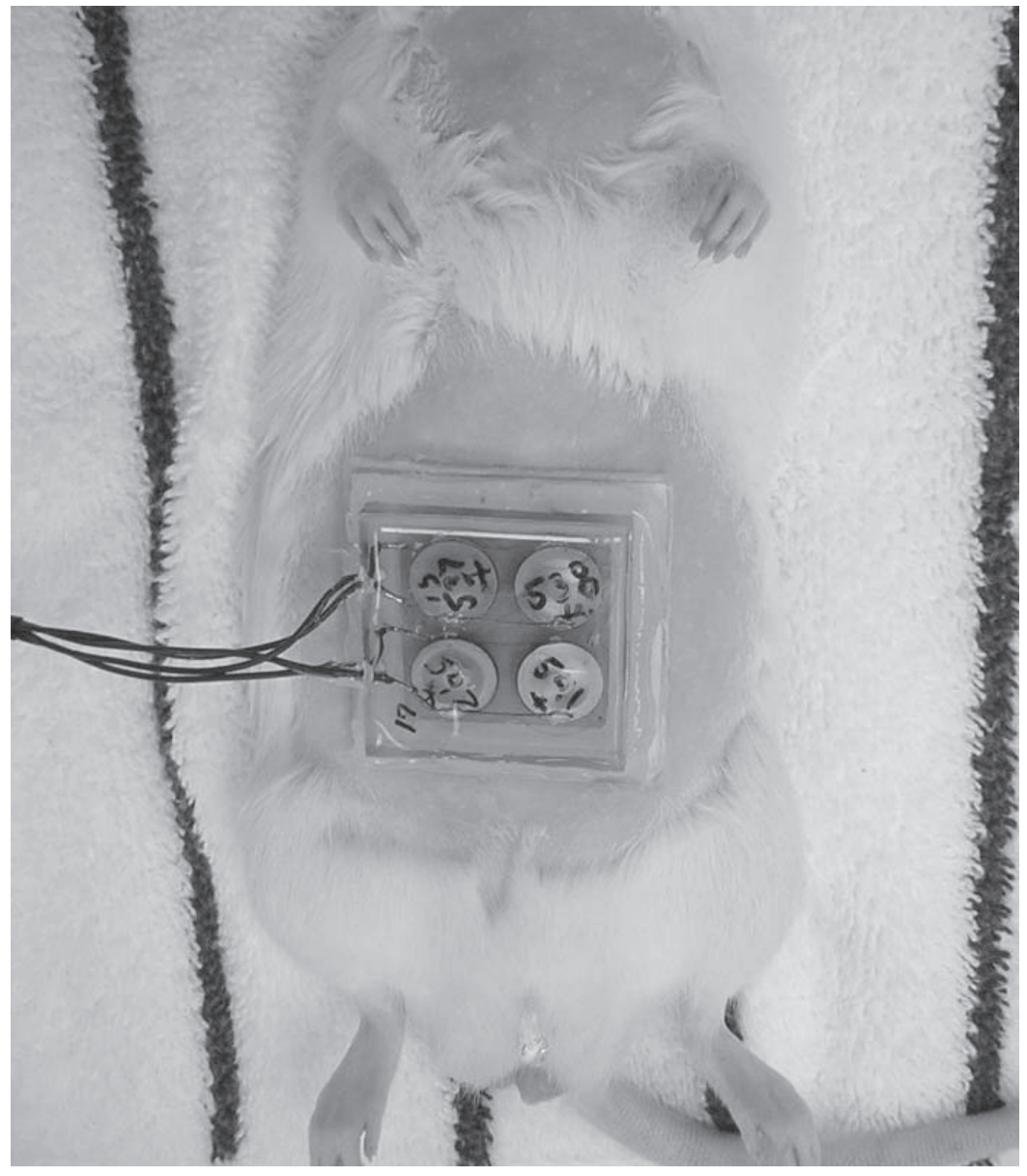

Figure I (A) For the cymbal array made up of four cymbal transducers, the cymbal elements were connected in parallel, encased in URALITE ${ }^{\oplus}$ polymer and arranged in a twoby-two elemental pattern. The dimensions of the array were $37 \times 37 \times 7 \mathrm{~mm}^{3}$ and it weighed less than $20 \mathrm{~g}$. (B) Photograph of a transdermal insulin delivery experiment with a rat placed in a dorsal decubitus position with the array attached. A I mm thick water tight standoff was arranged between the abdominal area and the array. The reservoir within the standoff was filled with insulin through a small hole in the back of the array. 
Precise, computer-controlled positioning of the hydrophone was performed by a Velmex Positioning System (Velmex Inc., East Bloomfield, NY). Pressure waves detected by the hydrophone were recorded by a digitizing oscilloscope. A computer-controlled exposimetry positioning system was used for automated scanning. The scanning step size for each device was $1 \mathrm{~mm}$ and the scanning area was $40 \times 40 \mathrm{~mm}^{2}$. Spatial peak-temporal peak $\left(\mathrm{I}_{\text {sptp }}\right)$ intensity were determined over a plane $1 \mathrm{~mm}$ from the array face using the hydrophone based on three scannings of the array for a mean and standard deviation of the intensity results. The intensity of cymbal transducer array was $\mathrm{I}_{\text {sptp }}=102.2 \pm 2.3 \mathrm{~mW} / \mathrm{cm}^{2}$.

\section{Animal experiments}

All procedures described in this report involving live animals were approved by the Institutional Animal Care and Use Committee (IACUC) at the Pennsylvania State University. A total of 16 experiments using eight Sprague-Dawley rats (350-550 g) were performed in four experimental groups with four rats in each group: one ultrasonic transdermal delivery and three subcutaneous injection groups. Rats were anesthetized with a combination of ketamine hydrochloride (60 mg/kg intramuscularly, Ketaject ${ }^{\circledR}$, Phoenix, St. Joseph, $\mathrm{MO})$ and xylazine hydrochloride $(10 \mathrm{mg} / \mathrm{kg}$ intramuscularly, Xyla-Ject $^{\circledR}$, Phoenix, St. Joseph, MO). In addition to its role in general anesthesia, xylazine was used to induce a temporary, but sustained (up to $12 \mathrm{hrs}$ ), hyperglycemia in rats (Pavlovic et al 1996; Kawai et al 1999).

For the ultrasonic transdermal delivery, the abdominal area of the rat was shaved using an electric shaver and a depilatory agent was applied to the skin to eliminate any remaining hair. After shaving, a 1-mm thick, water-tight standoff was attached (Figure 1b) between the skin and the array. With the rat in the dorsal decubitus position, a reservoir within the standoff was filled with insulin $\left(\operatorname{Humulin}^{\circledR} \mathrm{R}\right.$, rDNA U-100, Eli Lilly and Co., Indianapolis, IN) through a small hole in the array. Care was taken to remove all bubbles from the solution in the reservoir to prevent disruption of ultrasound transmission. The elapsed time from the initial injection of the anesthetic until the start of ultrasound exposure was no longer than 25 minutes. For the ultrasound exposure, the cymbal array was operated at $20 \mathrm{kHz}$ with an $I_{\text {sptp }}=100 \mathrm{~mW} / \mathrm{cm}^{2}$ for 60 minutes. After the 60 minutes ultrasound exposure, the array was removed and the skin examined for visible lesions.

The dose of insulin selected for the injection groups was based on published insulin doses used to control diabetes mellitus in other species and on pilot experiments (not reported). Humulin ${ }^{\circledR} \mathrm{R}$ Insulin $(100 \mathrm{U} / \mathrm{ml})$ was diluted with a $0.9 \%$ saline solution (Phoenix Pharmaceutical, Inc., St. Joseph, MO) to $0.5 \mathrm{U} / \mathrm{ml}$ and delivered subcutaneously (under the skin of the ventral abdomen) at $0.15,0.20$, or $0.25 \mathrm{U} / \mathrm{kg}$.

Blood was collected from the tail vein of each rat to obtain a baseline glucose level and, following insulin administration, additional samples were collected every 15 minutes for 90 minutes. For the ultrasonic transdermal delivery, the base line glucose level was measured at the beginning of the ultrasound exposure. The blood glucose level $(\mathrm{mg} / \mathrm{dl})$ for each sample was determined using the ACCU-CHEK ${ }^{\mathrm{TM}}$ blood glucose monitoring system (Roche Diagnostics Co., Indianapolis, IN). Each sample was tested at least twice to confirm the accuracy of the reading.

The data was corrected by subtracting the baseline glucose for each animal from each data point such that only changes in blood glucose were compared. Statistical analysis was performed using Microsoft Excel ${ }^{\circledR}$ (Microsoft Corp., Redmond, WA) and the data of blood glucose versus time were pooled for each group and analyzed as the mean and standard deviation. A t-test was used to analyze the statistical significance of the differences among the means of groups. The p-value was used to determine if the between-group differences are significantly greater than chance.

\section{Results}

Results of the ultrasound delivery compared with injection doses for the four groups are graphed as the decrease in the blood glucose level during the 90 minute experiment (Figure 2). Data were graphed and reported as the mean \pm standard deviation $(x \pm S D)$ of each group. Due to the anesthesia, the average initial glucose level at the beginning of the experiment was $340 \pm 69 \mathrm{mg} / \mathrm{dl}$ for the 16 experiments. Rats not anesthetized with xylazine would have a blood glucose closer to a normal level of $\sim 100 \mathrm{mg} / \mathrm{dl}$ (Harkness and Wagner 1995; Hillyer and Quesenberry 1997).

For direct subcutaneous injections with the dose of $0.15 \mathrm{U} / \mathrm{kg}$ and $0.20 \mathrm{U} / \mathrm{kg}$, the blood glucose level deviated little from the baseline value. Overall the glucose level varied no greater than $32 \mathrm{mg} / \mathrm{dl}$ from the initial value over a 90 minute experimental period for both doses. Yet for a subcutaneous insulin injection of $0.25 \mathrm{U} / \mathrm{kg}$, the blood glucose decreased by $190 \pm 96 \mathrm{mg} / \mathrm{dl}$ after 90 minutes. In comparison, the ultrasound produced a blood glucose decrease of $263 \pm 40 \mathrm{mg} / \mathrm{dl}$ at 90 minutes. A t-test analysis at 90 minutes indicated that all the groups were statistically different from each other at a p-level less than 0.01 . Visual examination of 


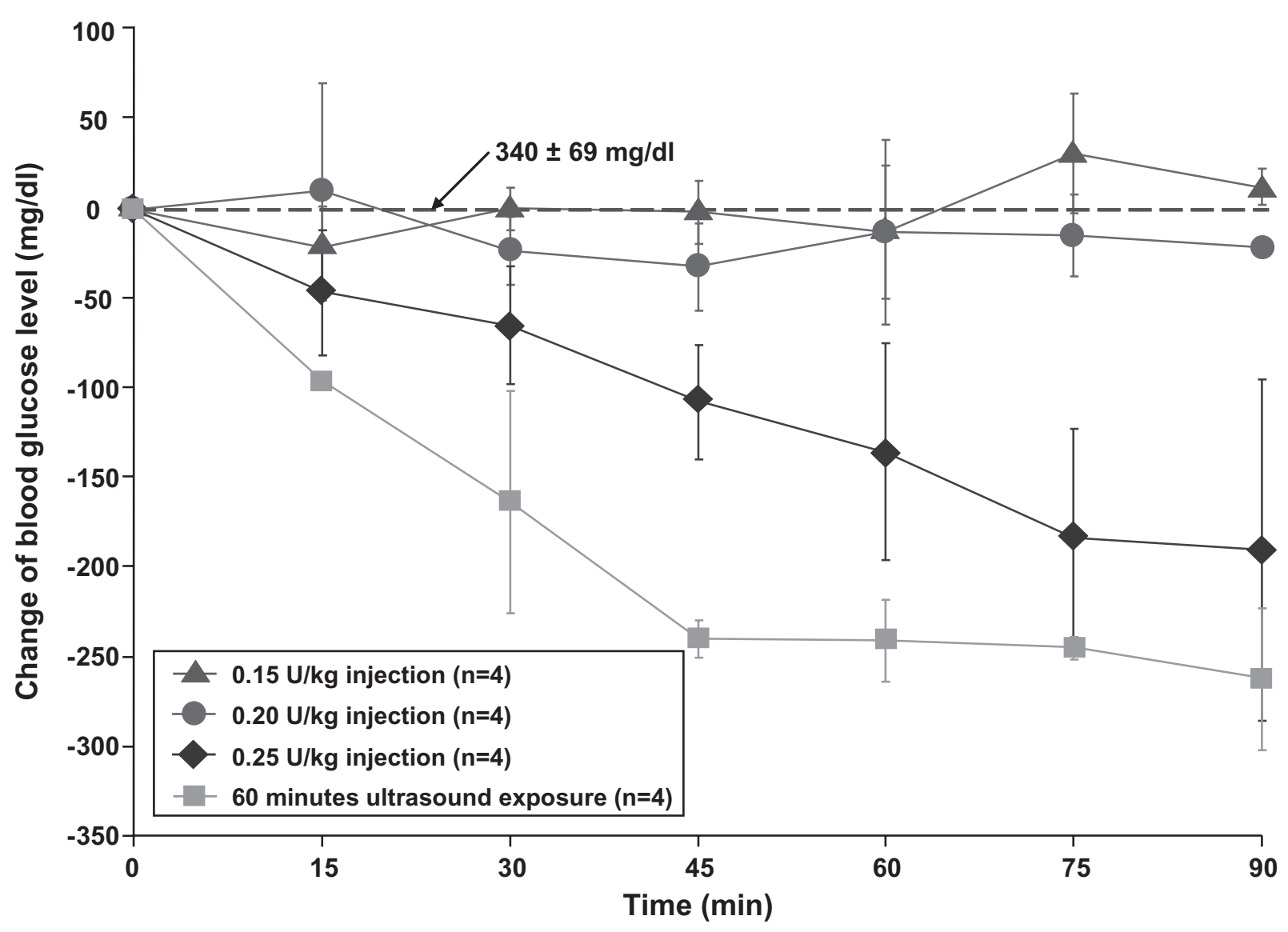

Figure 2 Over a period of 90 minutes, the blood glucose level of rats decreased to $-262 \pm 40 \mathrm{mg} / \mathrm{dl}$ at 90 minutes for ultrasound mediated transdermal insulin delivery ( $\square$ ) while there was less than $32 \mathrm{mg} / \mathrm{dl}$ change for both $0.15 \mathrm{U} / \mathrm{kg}(\bullet)$ and $0.20 \mathrm{U} / \mathrm{kg}(\boldsymbol{\Delta})$ injection groups. For the $0.25 \mathrm{U} / \mathrm{kg}(\bullet)$ injection group, the glucose level decreased to and $-190 \pm 96 \mathrm{mg} / \mathrm{dl}$ at 90 minutes.

the skin exposed to ultrasound did not indicate any damage or significant change to the skin.

\section{Discussion}

For humans to regulate their blood glucose level, the required insulin injection dose is $0.5-1 \mathrm{U} / \mathrm{kg} /$ day for adults and children and $0.8-1.2 \mathrm{U} / \mathrm{kg}$ for adolescents experiencing growth spurts (Lance et al 2002; Hodgson and Robert 2006). Direct subcutaneous injection doses for animals range from 0.1-0.4 U/kg subcutaneous (SC) for dogs and 0.1-0.5 U/kg (SC) for ferrets (Plumb 2005). Ranges are given since physiological variables have a direct effect on the specific blood glucose decrease from injections. As many clinicians and diabetes patients know, the body's glucose response to direct injections varies according to a host of variables such as body weight, fat percentage, exercise level, and composition of the most recent meal. Consistency of diet and exercise along with routine dose-glucose recording aids in the control of blood glucose. Without proper glucose control, diabetic complications may include renal failure, peripheral vascular disease, and limb amputation (Suetsugu et al 2007; Meeuwisse-Pasterkamp et al 2008).

To facilitate the ability of a diabetic patient to avoid repeated painful daily injections of insulin, a safe, lightweight, low-profile, inexpensive and potentially portable ultrasonic device is proposed. The goal was to develop an approximate relationship between dose levels from direct subcutaneous injections and noninvasive ultrasound at a $\mathrm{I}_{\text {sptp }}$ $\sim 100 \mathrm{~mW} / \mathrm{cm}^{2}$ for 60 minutes. While an exact mathematical relationship was not determined, the results in Figure 2 indicate that the ultrasound dose appears to be greater than an injection dose of $0.25 \mathrm{U} / \mathrm{kg}$ for rats. Not included in the results was a single rat experiment which used a direct injection dose of $0.44 \mathrm{U} / \mathrm{kg}$ which resulted in a rapid blood glucose decrease of $290.5 \pm 8 \mathrm{mg} / \mathrm{dl}$ after only 60 minutes. Given the rapid glucose decrease, the animal was removed from the experiment and this dose was determined to be too high for the rats. Yet the single point result can indicate that the ultrasound dose would be somewhere between injection dose levels of $0.25-0.44 \mathrm{U} / \mathrm{kg}$. Nevertheless the results are the 
first steps in determining a relationship between ultrasound intensity levels and insulin dose responses. Further experiments should explore the use of larger animals with a similar size and weight as humans or animal which are truly diabetic such as pancreatectomized pig.

In terms of human diabetes, a person is considered diabetic if their blood sugar level is above $126 \mathrm{mg} / \mathrm{dl}$ after eight hours of fasting. People without diabetes have fasting sugar levels that generally run between $70-110 \mathrm{mg} / \mathrm{dl}$. A glucose of $110-126 \mathrm{mg} / \mathrm{dl}$ is classified as impaired fasting glucose. In the oral glucose tolerance test, $140-200 \mathrm{mg} / \mathrm{dl}$ is impaired glucose tolerance and greater than $200 \mathrm{mg} / \mathrm{dl}$ is considered diabetic (Rifkin and Porte 1990; Shaw et al 1999; Carnevale Schianca et al 2003). For the last situation a diabetic person would need to inject enough insulin to reduce their blood glucose by about $100 \mathrm{mg} / \mathrm{dl}$. Both the ultrasound and direct injection of $0.25 \mathrm{U} / \mathrm{kg}$ achieve blood glucose level decreases of $190 \mathrm{mg} / \mathrm{dl}$ or greater.

Use of transdermal drug delivery techniques has practical clinical application to medications which need to be injected multiple times either daily or weekly. A recent review on ultrasound drug delivery states that "small-sized lowfrequency transducers need to be developed so that patients can wear them" (Pitt et al 2004). As with diagnostic ultrasound imaging, drug delivery using therapeutic ultrasound requires a delicate balance between safety and efficacy and requires careful scientific study. For a transdermal device to replace conventional needles, the bioeffects and safety of each device needs to be carefully evaluated since it will not matter how much of any drug can be transported if the skin is damaged or the procedure is painful.

\section{Acknowledgments}

This work was supported by the Department of Defense Technologies for Metabolic Monitoring Award Number W81XWH-05-1-0617. There are no conflicts of interest to report.

\section{References}

[AIUM] American Institute of Ultrasound in Medicine. 1998. Acoustic output labeling standard for diagnostic ultrasound equipment. Laurel, MD: American Institute of Ultrasound in Medicine.

Boucaud A, Garrigue MA, Machet L, et al. 2002. Effect of sonication parameters on transdermal delivery of insulin to hairless rats. J Control Release, 81:113-19.

Carnevale Schianca GP, Rossi A, Sainaghi PP, et al. 2003. The significance of impaired fasting glucose versus impaired glucose tolerance: importance of insulin secretion and resistance. Diabetes Care, 26:1333-7.

[CEDR] Congressionally Established Diabetes Research Working Group. 1999. Conquering Diabetes: A Strategic Plan for the 21st Century. NIH Publication No. 99-4398.
Doukas AG, Kollias N. 2004. Transdermal drug delivery with a pressure wave. Adv Drug Deliv Rev, 56:559-79.

Harkness JE, Wagner DJ. 1995. The Biology and Medicine of Rabbits and Rodents. Baltimore MD: Williams and Willkins.

Hillyer E, Quesenberry KE. 1997. Ferrets, Rabbits, and Rodents: Clinical Medicine and Surgery. Philadelphia PA: W.B. Saunders Co.

Hodgson BB, Robert J. 2006. Saunders Nursing Drug Handbook 2006. St. Louis, Missouri: Elsevier Saunders.

Hussain A, Claussen B, Ramachandran A, et al. 2007. Prevention of type 2 diabetes: a review. Diabetes Res Clin Pract, 76:317-26.

[IEEE] Institute of Electrical and Electronics Engineers. 1990. IEEE Guide for Medical Ultrasound Field Parameter Measurements. New York: Institute of Electrical and Electronics Engineers, Inc.

Johnson ME, Mitragotri S, Patel A, et al. 1996. Synergistic effects of chemical enhancers and therapeutic ultrasound on transdermal drug delivery. J Pharm Sci, 85:670-9.

Kawai N, Stummer W, Ennis SR, et al. 1999. Blood-brain barrier glutamine transport during normoglycemic and hyperglycemic focal cerebral ischemia. J Cereb Blood Flow Metab, 19:79-86.

Lance LL, Lacy CF, Goldman MP, et al. 2002. Quick Look Drug Book. Philadelphia, PA: Lippincott Williams and Wilkins.

Lee S, Nayak V, Dodds J, et al. 2005. Glucose measurements with sensors and ultrasound. Ultrasound Med Biol, 31:971-7.

Lee S, Newnham RE, Smith NB. 2004a. Short ultrasound exposure times for noninvasive insulin delivery in rats using the light weight cymbal array. IEEE Transactions on Ultrasonics, Ferroelectrics and Frequency Control, 51:176-80.

Lee S, Snyder B, Newnham RE, et al. 2004b. Noninvasive ultrasonic transdermal insulin delivery in rabbits using the light-weight cymbal array. Diabetes Technol Ther, 6:808-15.

Luis J, Smith NB, Meyer RJ. 2007. Rectangular cymbal arrays for improved ultrasonic transdermal insulin delivery. J Acoust Soc Am, 122:2022-30.

Machet L, Boucaud A. 2002. Phonophoresis: efficiency, mechanisms and skin tolerance. Int J Pharm, 243(1-2):1-15.

Maione E, Shung KK, Meyer RJ, et al. 2002. Transducer design for a portable ultrasound enhanced transdermal drug delivery system. IEEE Transactions on Ultrasonics, Ferroelectrics and Frequency Control, 49:1430-6.

Meeuwisse-Pasterkamp SH, van der Klauw MM, Wolffenbuttel BH. 2008. Type 2 diabetes mellitus: prevention of macrovascular complications. Expert Rev Cardiovasc Ther, 6:323-41.

Merino G, Kalia YN, Delgado-Charro MB, et al. 2003. Frequency and thermal effects on the enhancement of transdermal transport by sonophoresis. J Control Release, 88:85-94.

Meyer RJ, Dogan A, Yoon C, et al. 2001. Displacement amplification of electroactive materials using the cymbal flextensional transducer. Sensors Actuators, 87:157-62.

Mitragotri S, Kost J. 2004. Low-frequency sonophoresis: a review. Adv Drug Deliv Rev, 56:589-601.

Nanda A, Nanda S, Ghilzai NM. 2006. Current developments using emerging transdermal technologies in physical enhancement methods. Curr Drug Deliv, 3:233-42.

Newnham RE, Xu QC, Yoshikawa S. 1994. Metal-electroactive ceramic composite actuators. J Acoust Soc Am, 97:3215.

Newnham RE, Xu QC, Yoshikawa S. 1991. Transformed stress direction acoustic transducer. J Acoust Soc Am, 91:1198-9.

Park EJ, Werner J, Smith NB. 2007. Ultrasound mediated transdermal insulin delivery in pigs using a lightweight transducer. Pharm Res, 24:1396-401.

Pavlovic M, Wroblewski K, Manevich Y, et al. 1996. The importance of choice of anesthetics in studying radiation effects in the 9L rat glioma. Br J Cancer Suppl, 27:S222-5.

Pitt WG, Husseini GA, Staples BJ. 2004. Ultrasonic drug delivery - a general review. Expert Opin Drug Deliv, 1:37-56.

Plumb DC. 2005. Plumb's Veterinary Drug Handbook. Stockholm, Wisconsin: Pharma Vet Inc. 
Prausnitz MR, Bose VG, Weaver J. 1993. Electroporation of mammalian skin: A mechanism to enhance transdermal drug delivery. Proc Natl Acad Sci USA, 90:10504-8.

Prausnitz MR, Mitragotri S, Langer R. 2004. Current status and future potential of transdermal drug delivery. Nat Rev Drug Discov, 3:115-24.

Rifkin H, Porte D. 1990. Ellenberg and Rifkin's Diabetes. New York, NY: Elsevier Science.

Santoianni P, Nino M, Calabro G. 2004. Intradermal drug delivery by lowfrequency sonophoresis $(25 \mathrm{kHz})$. Dermatol Online, 10:24.

Schlicher RK, Radhakrishna H, Tolentino TP, et al. 2006. Mechanism of intracellular delivery by acoustic cavitation. Ultrasound Med Biol, 32:915-24

Shaw JE, Zimmet PZ, de Court M, et al. 1999. Impaired fasting glucose or impaired glucose tolerance. What best predicts future diabetes in Mauritius? Diabetes Care, 22:399-402.

Smith NB. 2007. Perspectives on Transdermal Ultrasound Mediated Drug Delivery. Int J Nanomed, 2:585-94.

Smith NB, Lee S, Maione E, et al. 2003a. Ultrasound mediated transdermal transport of insulin through in vitro human skin using novel transducer designs. Ultrasound Med Biol, 29:311-17.
Smith NB, Lee S, Shung KK. 2003b. Ultrasound-mediated transdermal in vivo transport of insulin with low-profile cymbal arrays. Ultrasound Med Biol, 29:1205-10.

Snyder B, Lee S, Newnham RE, et al. 2006. Ferroelectric transducer arrays for transdermal insulin delivery. J Mater Sci, 41:211-16.

Suetsugu M, Takebayashi K, Aso Y. 2007. Association between diabetic microangiopathy and vascular endothelial function evaluated by flowmediated vasodilatation in patients with type 2 diabetes. Int J Clin Pract, 61:920-6.

Tachibana K, Tachibana S. 1991. Transdermal delivery of insulin by ultrasonic vibration. J Pharm Pharmacol, 43:270-1.

The Whitaker Foundation. 2004. Biomedical Engineering and the Fight Against Diabetes, 2003 Annual Report. Arlington, VA: The Whitaker Foundation.

Wang Y, Thakur R, Fan Q, et al. 2005. Transdermal iontophoresis: combination strategies to improve transdermal iontophoretic drug delivery. Eur J Pharm Biopharm, 60:179-91.

Wu J, Chappelow J, Yang J, et al. 1998. Defects generated in human stratum corneum specimens by ultrasound. Ultrasound Med Biol, 24:705-10. 
